\title{
Quantification of multi-classes of endocrine-disrupting compounds in estuarine water
}

\begin{abstract}
Emerging pollutants known as endocrine-disrupting compounds (EDCs) are a contemporary global issue, especially in aquatic ecosystems. As aquaculture production through mariculture activities in Malaysia supports food production, the concentration and distribution of EDCs in estuarine water ecosystems may have changed. Therefore, this current study aims to prepare a suitable and reliable method for application on environmental samples. Besides, this study also presented the occurrence of EDCs pollutant in Pulau Kukup, Johor, where the biggest and most active mariculture site in Malaysia takes place. Analytical methods based on a combination of solid-phase extraction with liquid chromatography tandem mass spectrometry (Solid-phase extraction (SPE)-LC-MS/MS) have been modified and optimised to examine the level of targeted EDCs contaminant. In the current study, this method displays high extraction recovery for targeted EDCs, ranging from $92.02 \%$ to $132.32 \%$. The highest concentration detected is diclofenac $(<0.47-79.89 \mathrm{ng} / \mathrm{L})$ followed by $17 \beta$-estradiol $(\mathrm{E} 2)(<5.28-31.43 \mathrm{ng} / \mathrm{L})$ and $17 \alpha-$ ethynylestradiol (EE2) $(<0.30-7.67 \mathrm{ng} / \mathrm{L})$. The highest percentage distribution for the targeted EDCs in the current study is diclofenac, followed by EE2 and dexamethasone with the percentages of $99.44 \%, 89.53 \%$ and $73.23 \%$, respectively. This current study can be a baseline assessment to understand the pollution profile of EDCs and their distribution in the estuarine water of the mariculture site throughout the world, especially in Malaysia. Owing to the significant concentration of targeted EDCs detected.
\end{abstract}

Keyword : Endocrine disrupting compounds; Mariculture site;Solid-phase extraction; Estuarine water; Liquid chromatography mass spectrometer 